\title{
O Romance Histórico e Seus Desdobramentos na América Latina
}

\author{
La Novela Histórica y Sus Desdoblamientos en América Latina \\ Historical Romance and Its Developments in Latin America
}

\author{
Marcelo de Andrade Duarte ${ }^{1}$
}

\begin{abstract}
Resumo
Considerando a importância do entrecruzamento de história e ficção, especialmente no contexto da América Latina, este trabalho tem por objetivo apresentar uma proposta de uma história da literatura de narrativas latinoamericanas que estabelecem relações diretas com episódios históricos. A motivação para tal pensamento se deve, especialmente, pela efervescência de textos ficcionais de cunho histórico nas últimas décadas do século XX, questão que permanece no século XXI. Tais narrativas se apresentam como um discurso semelhante ao da história, dotado de verdade, um discurso cuja versão aponta para uma versão o mais fiel possível aos eventos e personagens do passado histórico.
\end{abstract}

Palavras-Chave: Literatura Comparada; História da Literatura; América Latina.

\section{Resumen}

Considerando la importancia del entrecruzamiento de historia y ficción, especialmente en el contexto de América Latina, este trabajo tiene por objetivo presentar una propuesta de una historia de la literatura de narrativas latinoamericanas que establecen relaciones directas con episodios históricos. La motivación para tal pensamiento se debe, especialmente, por la efervescencia de textos ficticios de cuño histórico en las últimas décadas del siglo XX, cuestión que permanece en el siglo XXI. Tales narrativas se presentan como un discurso semejante al de la historia, dotado de verdad, un discurso cuya versión apunta a una versión lo más fiel posible a los eventos y personajes del pasado histórico.

Palabras claves: Literatura Comparada; Historia de la Literatura; América Latina.

\begin{abstract}
Considering the importance of the interweaving of history and fiction, especially in the context of Latin America, this work aims to present a proposal for a literary history of Latin American narratives that establish direct relationships with historical episodes. The motivation for such a thought, especially, by the effervescence of fictional texts of historical nature in the last decades of the 20th century, an issue that remains in the 21st century. Such narratives are presented as a discourse similar to the story, endowed with truth, a discourse whose version points to a version as thorough as possible to the events and characters of the historical past.
\end{abstract}

Keywords: Comparative Comparative Literature; History of Literature; Latin America.

\section{Definições Prévias}

O estudo das relações entre literatura e história sempre integrou as preocupações dos estudiosos; já entre os anos 335 e 323 a.C. Aristóteles na Poética, apesar de realizar uma análise exclusivamente da tragédia, no parágrafo 50 do livro IX o filósofo tece um comentário

\footnotetext{
${ }^{1}$ Doutorando em Teoria da Literatura, Pontifícia Universidade Católica do Rio Grande do Sul (PUCRS). E-mail: marcelo.duarte.002@acad.pucrs.br. Trabalho apresentado no III Encontro Humanístico Multidisciplinar e II Congresso Latino-Americano em Estudos Humanísticos Multidisciplinares, Jaguarão/RS, Brasil, 2017.
} 
acerca das relações entre literatura e história, que abriria caminho para os futuros estudos das relações entre tais discursos. Para Aristóteles, o que aproxima os dois discursos é a presença de um mito, que na terminologia atual se equivale à narrativa; já a distinção entre eles não se dá pelo modo de narrar (prosa/verso), mas pela natureza da representação. Ou seja, a literatura tem por natureza a verossimilhança - ilusão da realidade - e a história tem um compromisso com a veracidade - factualidade -, algo que não se impõe à literatura. Diante disso, Aristóteles afirma que existe uma incompatibilidade entre os discursos literário e histórico, dadas as diferenças citadas anteriormente. Porém, Aristóteles crê que a literatura é mais interessante que a história, já que essa trabalha com particularidades e aquela, universalidades.

A ideia de fazer uma história da literatura de textos que estabeleçam relações diretas com episódios históricos surge, inicialmente, por uma proximidade com o tema devido a pesquisas desenvolvidas no mestrado em Letras da Universidade Federal de Pelotas. Outra motivação se deve pela efervescência de textos ficcionais nas últimas décadas do século XX, questão que permanece no século XXI. Os romances de cunho histórico se apresentam como um discurso semelhante ao da história, dotado de verdade, como um discurso cuja versão aponta para uma versão o mais fiel possível aos eventos e personagens do passado histórico.

A maioria destes romances recorrem a eventos passados em que aparecem pessoas reais inseridas em um mundo localizado em um espaço e tempo também reais. Exemplificando a afirmação anterior, temos o escritor cubano Alejo Carpentier e o autor mexicano Jorge Volpi. O primeiro, em El arpa y la sombra ficcionaliza dois personagens históricos, o Papa Pio IX e Cristóvão Colombo, narrando a repercussão que a "descoberta" da América teve para o mundo, especialmente, para a igreja católica. Já o autor mexicano em $E l$ fin de la locura tematiza o auge e a queda das utopias revolucionárias da esquerda latinoamericana através de Aníbal Quevedo, um psicanalista, que durante a obra dialoga com diversos personagens da história, entre eles, Barthes, Lacan e Kristeva, na revolta de Paris em maio de 1968, e Fidel e Allende no processo revolucionário de Cuba e Chile.

David Perkins em "História da literatura e narração" define que para a escrita de uma História da Literatura é necessário definirmos nossos marcos temporais, início e fim da narrativa. Nossa história iniciaria, então, considerando o tempo do enunciado, no início do século XVI, com a obra Xicoténcatl, de autoria anônima que daria conta da história da América Latina desde a chegada de Hernán Cortés até a morte de Xicoténcatl filho em 1521, e finalizaria já em um período próximo a nossa contemporaneidade nas narrativas pós-ditaduras militares. Com isso, daríamos conta de quase cinco séculos de história da América Latina. Certamente deveríamos ter realizado um recorte temático, não apenas pela categoria teórica 
do romance histórico, pois ao realizarmos a pesquisa de obras que poderiam compor nossa História da Literatura, cada vez mais tínhamos acesso a diferentes textos, que aparentemente não tinham fim, o que se apresentou como um grande problema.

Após o surgimento do romance histórico clássico na Europa, surge também na América Latina narrativas que visavam a invenção de uma tradição. Segundo Figueiredo (1996) um panorama do romance latino-americano, em comparação com o europeu, permite a percepção de que tal literatura tornou-se estigmatizada por desenvolver mais o esquecimento do que a memória.

Nossa proposta neste trabalho é a de delimitar um corpus de textos literários latinoamericanos em que há o entrecruzamento de literatura e história. Esse corpus será constituído apenas por romances produzidos no lócus de enunciação previamente indicado. A lista desses textos será indicada de forma cronológica em capítulos organizados em torno de alguns quadros teóricos, entre eles: Romance Histórico, Novo Romance Histórico, Romance Policial-histórico e outros. Para a classificação das obras dentro desses esquemas, seriam realizadas análises dos textos de acordo com as indicações teóricas dessas categorias.

Tomaremos como nosso conceito de romance o exposto em "Epos e Romance" (que discute as relações entre romance e epopeia), de Bakhtin (1994), visto que as reflexões quanto à necessidade de uma perspectiva sociológica ao abordarmos literatura e estética é fundamental para que possamos entendê-las. No texto citado anteriormente, Bakhtin não propõe nenhuma descrição do entrecruzamento entre literatura e história, porém podemos depreender que o local onde a literatura e a história se encontram mais claramente é no romance, já que esse é um gênero que abstrai todos os gêneros possíveis em sua forma, que está em eterna metamorfose (o que impede uma descrição da forma do romance). No romance temos a presença de uma narrativa, o que nos propicia um elemento concreto de análise entre literatura e história, porque qualquer narrativa representará o passado, mesmo que nem todas as formas literárias estabeleçam um diálogo claro com a história.

Para Bakhtin, o romance é o gênero de maior relevância cultural, o único gênero ainda inacabado, pois está sempre em contato com o presente, em conexão com o mundo, não um mundo fechado, como na epopeia, esse contato com a vida é o que mantém - e manterá - o romance vivo. O romance também se consolida, em Bakhtin, como um gênero híbrido, que tem como uma das características de estilo a presença de inúmeros discursos (o dialogismo), já que se aproveita dos distintos discursos que circulam na sociedade. Como dito anteriormente, o romance apresenta discursos que estão em eterno conflito o que coloca, assim, a literatura em diálogo com discursos diferentes do literário (em oposição ao 
pensamento formalista). Sendo assim, de acordo com o caráter híbrido do romance, o mesmo, em algum momento, vai propor uma relação híbrida com a história, pensamento preponderante para o conceito de romance histórico, porém como veremos adiante, segundo Lukács, mesmo com temática histórica, muitos textos não se enquadram nesse conceito. Ao não se enquadrarem em tal conceito, buscaremos outros para realizarmos a nossa divisão de capítulos de acordo com outros referenciais teóricos das relações entre literatura e história.

\section{Ficcionalização da História na Literatura Latino-americana}

\subsection{O romance histórico de matriz scottiana}

A proposta de um gênero chamado romance histórico, tem sua origem no texto " $\mathrm{O}$ Romance Histórico”, de Lukács (escrito durante seu exílio na Rússia), primeira reflexão teórica moderna acerca da relação entre literatura e história (desde o parágrafo 50 da Poética, de Aristóteles, não se pensava, teoricamente, essa questão). Nessa obra, Lukács define o modelo conceitual para descrever e refletir a representação da realidade histórica realizada pela literatura. Lukács afirma que a relação entre literatura e história se dá essencialmente no romance, por ser o romance um gênero híbrido.

Ao propor a especificidade do romance histórico, Lukács afirma que todos necessitam de um tema histórico, porém para sê-lo o que importa é a história como representação ou figuração, ou seja, é necessário que o escritor se volte para o passado com uma visão calcada no presente. Esse romance histórico decorre de uma nova consciência que transforma a história em uma experiência do povo, em que o povo se sinta como parte integrante da mesma, diferente do que ocorria na epopeia, em que era impossível a população visualizar-se naquela história, devido à distância épica.

Lukács define o momento das revoluções (sobretudo a Francesa) como preponderante para o surgimento do romance histórico, pois antes o homem não se sentia pertencente à história, já que a história elevava os deuses e reis, não considerando as massas. Quando as massas passam a fazer parte da história, o passado deixa de ser distante e começa a ser importante, pois explica o presente. Através do sentimento de pertencimento à história, os sujeitos reconhecem sua importância para a construção desse presente. Tais sujeitos reconhecem sua existência como algo historicamente construído e passam a ver no passado algo que determina sua existência cotidiana, dizendo-lhes respeito diretamente.

Para pensar tais questões na literatura, Lukács refere-se especificamente a Walter Scott (Edimburgo, Escócia, 1814-1819) que em suas obras, primeiramente Waverley (1814), depois Ivanhoé (1819), expôs alguns importantes acontecimentos da história do Reino Unido, e que o 
filósofo húngaro define como o criador de um gênero híbrido de história e ficção (em pleno romantismo europeu), o romance histórico. Ao analisar as obras de Walter Scott, Lukács define que no romance histórico clássico o passado histórico é representado de forma a anular a intervenção do tempo da enunciação sobre o tempo da diegese, ou seja, não se pode "reconstruir" a história, mas sim tentar descrever o passado tal qual ele ocorreu. Sendo assim, volta-se ao passado para afirmar e confirmar valores do presente, pois havia uma consciência histórica que considerava um passado (retratando os grandes eventos da história) onde encontraríamos relevância para o presente.

$\mathrm{Na}$ tentativa de reconstrução do passado como ocorreu, Walter Scott mesclava fatos com ficção, acrescentando personagens fictícios que não participaram da história. Como protagonista do romance histórico, Scott colocava um herói mediano, ou seja, um tipo social que representava uma coletividade, um homem comum (que terá papel relativamente decisivo no passado histórico) em que todos pudessem se reconhecer, para, assim, não utilizar personagens históricos para a construção do romance.

Scott não utilizava os grandes sujeitos da história, já que, ao fazê-lo seria necessário ficcionalizá-lo, sendo assim, não teríamos mais um espelho do passado, mas sim uma refiguração do mesmo. Dessa maneira, as grandes personalidades da história aparecem como pano de fundo da narrativa, assim como os grandes acontecimentos históricos oficiais, pois também seria impossível reconstruí-los tais como ocorreram.

Quanto à concepção ideológica do gênero aqui em questão, nota-se que ele se prende ao ideal de história hegemônica que compreende ao "positivismo histórico" em que o historiador, tendo acesso às fontes primárias, seria capaz de reconstituir qualquer momento histórico. Já quanto à forma, notamos que o romance histórico proposto por Lukács, aproxima-se de uma das características da épica, conforme análise de Bakhtin, onde há um passado absoluto, em que Scott coloca a história ao fundo, como cenário, tendo um grande cuidado para não a alterar.

Segundo Lukács, no romance histórico não podemos ter personagens históricos como protagonistas, sim pessoas comuns para que o povo se sinta pertencente à história. Ao colocar um personagem histórico como protagonista, o romance está de certa forma modificando a história, ou seja, mesmo com temática histórica, poucos serão romances históricos, pois seriam apenas aqueles em que o passado interfere sobre o presente e não os que andam no caminho contrário, ou seja, romances que repensem a história, não poderiam se inserir no conceito de Lukács. 
No contexto da américa-latina, a obra Xicoténcatl (1826), de autoria anônima, é considerada, segundo Menton (1993), o primeiro registro desse gênero, sua história narraria o encontro entre duas civilizações, a pré-colombiana e a espanhola. Ainda segundo Menton, o pioneiro em romance histórico no Brasil é José de Alencar com O guarani (1857), Iracema (1865), As Minas de Prata (1862-65) e A Guerra dos Mascates (1865).

Além desses romances iniciais, podemos citar diversos outros, com base nos estudos de José Ribeiro em O romance histórico na literatura brasileira (1976) e de Flávio Loureiro Chaves em História e Literatura (1991): Os Farrapos (1877), de Oliveira Belo; A Moreninha e O Moço Loiro, de Joaquim Manoel de Macedo; A história da conjuração (1860), de Joaquim Norberto; Padre Belchior de Pontes, de Júlio Ribeiro; O Matuto (1878) e Lourenço (1881), de Franklin Távora; O Encilhamento, de Visconde de Taunay; A Marquesa de Santos (1925), As maluquices do Imperador (1927), O Príncipe de Nassau (1928), Um Sarau no Paço de São Cristóvam, A Bandeira de Fernão Dias (1928), El-Dorado, O sonho das Esmeraldas, Romance de Prata, Os irmãos Leme, Ouro de Cuiabá e Capitão Jagunço, todos de Paulo Setúbal, sendo os sete últimos pertencentes ao chamado ciclo dos bandeirantes; $A$ Balaiada - Romance do tempo da Regência (1927), de Viriato Corrêa; O Rei Cavaleiro, de Pedro Calmon; Continente (1949), de Érico Veríssimo; Fome em Canaã, de Agripa Vasconcelos; A Muralha (1954), de Dinah Silveira de Queirós; Tocaia Grande (1984), de Jorge Amado.

Além dos mencionados, muitos outros teriam que ser examinados a fim de analisar sua estrutura e decidir se seriam postos no presente capítulo, no seguinte que trataria do novo romance histórico latino-americano que revisam a história oficial ou, ainda, em um capítulo dedicado a metaficção historiográfica, entre eles cabe destacar A prole do corvo, de Assis Brasil e Boca do Inferno (1989), de Ana Miranda².

\subsection{Novo Romance Histórico}

Seymour Menton propõe o conceito de novo romance histórico ${ }^{3}$, vinculado a um "novo" paradigma de representação do passado, decorrente de um corpus literário específico, essencialmente, da América Latina, a partir de 1949, já que Menton considera El Reino de

\footnotetext{
${ }^{2}$ Sobre a obra de Ana Miranda, caberia um estudo que visasse responder a uma pergunta "É possível contar a história do Brasil pelas chamadas obras de autoria (Boca do Inferno, O retrato do rei, Clarice, A última quimera, Desmundo, Yuxin, Dias e Dias e Amrik) de Ana Miranda?" No entanto, não pode ser tema de nossa proposta visto que não contemplaria a América Latina, apenas o Brasil.

${ }^{3}$ O livro La nueva novela histórica de América Latina, 1949- 1992, de Menton - professor da Universidade da Califórnia - é resultado de cinco anos de pesquisa, tendo sido analisados 367 romances históricos publicados entre 1949 e 1992.
} 
Este Mundo, de Alejo Carpentier, como o primeiro novo romance histórico. Para explicar o auge do romance histórico na América Latina, Menton propõe duas explicações: a proximidade do quinto centenário da chegada de Colombo à América, pois esse momento provocou diversos questionamentos sobre o papel da América Latina no mundo, ou a busca por um escapismo da realidade, buscando na história, esperanças para a América Latina. Quanto à primeira ideia, destaca-se que Cristóvão Colombo aparece como protagonista de diferentes romances publicados no período analisado por Menton. $\mathrm{O}$ conceito proposto por Menton, pela própria terminologia, percebe-se que é vinculado à tradição teórica do romance histórico de Lukács, porém o autor em nenhum momento propõe uma revisão desse conceito. Lukasz Grützmacher (2006), estudioso da Universidade de Varsóvia, criticou o fato de Menton apenas enfatizar o novo, sem recuperar o conceito de Lukács.

Como diferencial do que foi teorizado por Lukács, Menton afirma que no novo romance histórico existe uma problematização da história, em oposição ao positivismo histórico, que Lukács estudou a partir dos romances de Walter Scott. Contudo, na proposição do "novo" Menton refere-se a conceitos já tratados por Lukács, já que no novo romance histórico teríamos a história não como tema, mas como uma representação "que traz o passado para perto de nós e o torna experenciável” (LUKÁCS, 2011: 73).

Menton enumera seis características dos novos romances históricos, no entanto entre elas existem algumas que se assemelham ao que foi postulado por Lukács, dentro das quais sublinhamos a intertextualidade e a dialética, pois no momento em que o filósofo húngaro propõe que existe uma relação entre história e literatura, ele está se valendo de tais conceitos. Assim, todo o romance histórico, mais ainda, todo o romance é intertextual e dialógico por excelência, visto que, conforme Bakhtin, o dialogismo é encontrado em qualquer discurso, não apenas no literário. Quanto a tais características do novo romance histórico que viriam a romper com o paradigma proposto por Lukács, Grützmacher afirma que são muito superficiais, causando mais confusão que esclarecimentos.

A proposta de Menton aparece muito mais com um caráter didático e histórico da literatura latino-americana, visto que carece de fundamentação teórica, porque para ele basta a questão do distanciamento entre o autor e a história narrada (cf. a definição de Imbert). Levando em consideração esse pressuposto teórico, Menton descarta alguns romances cuja diegese fosse contemporânea ao escritor, citando o exemplo do romance de Gabriel García Márquez, Cem Anos de Solidão, pois a geração mais jovem coincide com a do escritor. Todavia, entre outras confusões causadas por Menton, ao analisar as características do novo 
romance histórico, cita a mesma obra de García Márquez como sendo um novo romance histórico, porque tem em suas características a intertextualidade e a carnavalização.

Ao criticar o conceito proposto por Menton, Grützmacher traz-nos um artigo de Fernando Ainsa em que não é possível fazer distinção entre novos romances históricos e tradicionais, pois todo o gênero passa por renovações (as relações entre literatura e história são historicamente definidas) e o que mais importa é analisar a atitude crítica com que os escritores contemporâneos "enfrentam" a historiografia oficial. Assim, o importante seria entender que os escritores hispano-americanos tendem a concentrar-se nos temas históricos pelo desejo de questionar e reescrever a versão estereotipada do passado (GRÜTZMACHER, 2006) imposta pelos colonizadores. Portanto, segundo Ainsa, o que caracteriza o romance histórico contemporâneo é sua posição paródica frente ao discurso historiográfico oficial.

Ainda conforme Ainsa, Grützmacher afirma que os romances têm duas tendências, os que pretendem reconstruir o passado e os que o desconstrói. Por esse caminho, o autor referese a duas forças encontradas nos romances históricos, a centrípeta (romances dominados por essa força seriam os tradicionais), reconstrução do passado, e a centrífuga (romances dominados por essa força equivaleriam aos pós-modernos), desconstrução dos discursos que tenham pretensão de ser o verdadeiro passado.

Como conclusão de seu artigo, Grützmacher qualifica de história pós-oficial aquela que seria uma projeção do passado que não visa buscar uma verdade histórica e que tem como fundamento que "todo discurso sobre el pasado es ideologizado, dominado por la retorica y subordinado a las convenciones" (GRÜTZMACHER, 2006: 64). Desse modo, o discurso da história pós-oficial serve-se de uma série de recursos retóricos, jogando com as convenções para demonstrar sua própria ideologia. Assim, o discurso pós-oficial é um dos modos de olhar para o passado, bem como a metaficção historiográfica.

El arpa y la sombra, El Reino de este Mundo, El siglo de las luces e Concierto Barroco, de Alejo Carpentier; Borges; La muerte de Artemio Cruz e Terra Nostra, de Carlos Fuentes; Vigilia del Almirante, de Augusto Roa Bastos; La Guerra del fin del mundo, El paraíso en la otra esquina, El sueño del celta, de Mario Vargas Llosa; Em liberdade, de Silviano Santiago; El general en su laberinto e Cien anõs de soledad, de Gabriel Garcia Marquez; Mad Maria e Galvez, o Imperador do Acre, de Márcio Souza; Cães da Província, de Luiz Antônio de Assis Brasil; A casca da serpente, de José J. Veiga; El mar de las lentejas, de Antonio Benitez Rojo; Las puertas del mundo. Una autobiografía hipócrita del Almirante, do mexicano Herminio Martínez; Palinuro de México e Noticias del Imperio, de Fernando del Paso; Los perros del paraíso, de Abel Posse; La loma del ángel e El mundo 
alucinante, de Reinaldo Arenas; Morada Interior, de Angelina Muñiz; La isla de Róbinson, de Arturo Pietri; Martes Tristes, de Francisco Simon (segundo Menton, esse seria o único exemplo dessa modalidade de romance histórico no $\mathrm{Chile}^{4}$, porém acrescentaremos mais um); Un viejo que leía novelas de amor, de Luís Sepúlveda.

\subsection{Testemunho em Narrativas Ditatoriais e Pós-ditatoriais}

Esse capítulo necessitaria de um aprofundamento em uma questão tão cara à América Latina: a violência proveniente de ditaduras militares. O tema do ditador já aparece por volta de 1838 no conto "El matadero", de Esteban Echeverría, e também na obra Facundo: civilización y barbárie, de Sarmiento, publicada em 1845.

Surgem depois narrativas que colocam os ditadores como personagens principais, empregando a palavra como forma de resistência e também pela possibilidade de os escritores apresentarem a faceta humana e social dos ditadores que normalmente são vistos como personagens míticos. Segundo Navarro (1989), a humanização do personagem é a grande contribuição dos romances de ditador. Os romances-históricos de ditadores que trazemos como referencia são: El Señor Presidente, de Miguel Ángel Asturias; El recurso del método, de Alejo Carpentier; Yo el Supremo, de Augusto Roa Bastos; El otoño del patriarca, de Gabriel Garcia Marquez; La fiesta del Chivo, de Mario Vargas Llosa.

Além da questão do romance de ditador, surgem diversas narrativas escritas durante períodos de ditaduras militares como modo de resistência, bem como outras que se destinam a fazer denúncias das práticas desses regimes, destacamos entre esses romances os seguintes: Reflexos do Baile e Quarup, de Antonio Callado, Incidente em Antares, de Érico Veríssimo, Viva o Povo Brasileiro, de João Ubaldo, Tropical Sol da Liberdade, de Ana Maria Machado, Sombras de Reis Barbudos, de José J. Veiga, Primavera con una esquina rota, de Mario Benedetti, Libro de Manuel, de Julio Cortazar; Estrella distante e Nocturno de Chile, de Roberto Bolaño; As Meninas, de Lygia Fagundes Telles; Respiración Artificial, de Ricardo Piglia; Antonio Skármeta, El ciclista de San Cristobal, Ardiente paciência e La muerte juega a ganador, de Ramón Díaz Eterovic.

\footnotetext{
${ }^{4}$ Uma explicação possível dada por Menton é de que os autores chilenos têm uma preocupação maior com um passado mais imediato, ou seja, o golpe militar contra o regime de Allende em 1973, a ditadura de Pinochet e o exílio de muitos de seus escritores.
} 


\subsection{Hibridez de gêneros: o romance histórico-policial}

Além de ser fruto da pós-modernidade que faz a desconstrução e a hibridização de gêneros, a união do romance histórico com o policial é também um fenômeno mercadológico. Beatriz Velloso, em reportagem da revista Época em 2003 indicava a invasão de um gênero que não é nenhuma novidade, mas que nunca teve tanto sucesso, garantido pela união de dois gêneros que sempre tiveram leitores fiéis:

Há desde mortes na Grécia Antiga até investigadores na Rússia czarista do século XIX. Isso sem deixar de passar por crimes insolúveis na Idade Média e assassinatos em série durante a corrida do ouro, na Califórnia. Nos Estados Unidos, a crítica elogiou The Dante Club, cuja ação se passa em Boston, em 1865 (no livro, um grupo de tradutores de Dante é surpreendido por mortes que lembram as punições descritas no Inferno da Divina Comédia). Há uma justificativa para os lançamentos no gênero híbrido: tanto o romance policial quanto o histórico têm público fiel e leitura garantida. É a união de dois estilos que vendem bem (VELLOSO, 2003).

Muitos desses romances policiais com ambientação histórica utilizam essa apenas como pano de fundo, sem problematizá-la. Na reportagem mencionada anteriormente, o escritor Garcia-Roza ressalta a não problematização da história em alguns romances: "Salvo exceções, isso serve apenas para dar um aspecto pitoresco, e quase sempre encobre alguma falha da obra". Diante dessa afirmação, a seleção dos textos a serem inseridos nesse capítulo considerará apenas aqueles nos quais a história seja um elemento essencial. Um exemplo dessa utilização da história é o romance histórico-policial de Umberto Eco, O Nome da Rosa, que investiga diversos assassinatos de monges ocorridos na Itália do século XIV.

As seguintes obras viriam a integrar esse capítulo: A Primeira História do Mundo, de Alberto Mussa (cuja narrativa remete ao que foi considerado o primeiro assassinato do Brasil ocorrido no antigo Rio de Janeiro em 1567); Memórias de Aldenham, de Antonio Callado (conta a história de um grupo de latino-americanos ${ }^{5}$ - um paraguaio, uma chilena, uma brasileira, um boliviano, um venezuelano e um anglo-brasileiro - que buscam exílio na Inglaterra nos anos 1940 devido à repressão política em seus respectivos países); Agosto, de Rubem Fonseca (ambientado em agosto de 1954 apresenta alguns episódios da história brasileira que culminaram com o suicídio de Getúlio Vargas); Santa Evita, de Tomás Eloy Martinez (narra quatro histórias relacionadas com a primeira-dama argentina Eva Duarte de Perón: o destino do corpo de Eva, a história de Eva enquanto viva, a história dos militares

\footnotetext{
${ }^{5}$ Em "A casa assassina ou a Inglaterra vista da Américalatíndia", Lígia Chiappini afirma que o conflito entre esses personagens metaforiza a complicada relação e os conflitos de identidade dos habitantes da América do Sul. In: Cadernos Comarca (Imagens da Europa na Literatura Brasileira), São Paulo, Centro Ángel Rama /Humanitas, 2001 , p. $35-49$
} 
envolvidos na operação do desparecimento do corpo e a história do autor enfrentando a escrita do livro). Para aumentar o corpus de romances históricos-policiais seria necessária uma pesquisa e análises mais aprofundadas, pois poderíamos citar outros romances policiais da américa-latina, como O jogo de Ripper, de Isabel Allende, O Xangô de Baker Street, de Jô Soares, ou Alvo Noturno, de Ricardo Piglia, entre outros, porém não poderíamos afirmar a relevância de tais obras considerando a temática desse capítulo.

\subsection{Romance Histórico na Contemporaneidade}

No texto "O Romance Histórico ainda é possível", Fredric Jameson questiona se o romance histórico seria minimamente possível no quadro de uma estética modernista? Linda Hutcheon não acreditava no romance histórico na modernidade, pois acusava o modernismo de ter um fechamento formalista, o que acabava com o referencial externo.

Para sua reflexão, Jameson retoma as proposições de Lukács, porém descola o romance histórico da matriz scottiana, afirmando, diferente de Lukács, que Walter Scott não inventou o romance histórico, mas uma variante do mesmo: o drama de costumes, aceitando que o romance histórico não tem uma única matriz. $\mathrm{O}$ drama de costumes se organiza, eticamente, pelo dualismo bem e mal, indo à busca de um nacionalismo (do Romance Histórico) através desse dualismo.

Para Jameson a modernidade coloca em crise o modelo scottiano do drama de costumes, já que, por exemplo, George Eliot não se enquadra no modelo scottiano do drama de costumes, porque a autora não acredita mais nesse modelo maniqueísta da disputa entre bem e mal. No contexto modernista a questão fica mais complexa, pois não é mais possível enquadrar a disputa entre bem e mal (drama de costumes).

Desse modo, no pensamento de Jameson o romance histórico não é possível na modernidade: "O romance histórico não deve mostrar nem existências individuais nem acontecimentos históricos: mas a intersecção de ambos." (JAMESON, 2007: 192). Pois tomando Ulisses, de Joyce, como o romance que inaugura a estética modernista. O que caracterizaria a estética modernista seria a "hiper" subjetividade, com isso perde-se a objetividade com relação ao passado, não sendo possível apresentar a intersecção entre individualismo e acontecimentos históricos, pois o enfoque modernista está nas subjetividades “[...] o subjetivismo intensificado do texto modernista torna cada vez mais difícil discernir a objetividade da dimensão histórica." (JAMESON, 2007: 200). Ainda tomando como exemplo Ulisses, nesse romance as personagens não vivem experiências históricas a partir dos eventos que se apresentam, impossibilitando o romance histórico. 
Apesar das afirmações de Jameson, ainda encontramos romances históricos sendo produzidos, considerando o Brasil (certamente ao realizarmos uma pesquisa detalhada encontraremos produções contemporâneas dos demais países da América Latina). Alguns exemplos de textos pertencentes a esse gênero publicados nos últimos dois anos são os seguintes: Em breve tudo será mistério e cinza, de Alberto Reis (compreende o período regencial a partir de 1825, indo até a Revolução Liberal de 1842, trazendo a narrativa de um joalheiro francês - que futuramente seria avô de Santos Dumont - que chega ao brasil para trabalhar na mineração, convivendo com escravos e famílias tradicionais); Quatro Soldados, de Samir Machado de Machado (tematiza o sul dos anos 1750, narrando a história de soldados do Regimento dos Dragões que apoiava ações militares portuguesas em conflitos com índios guaranis, jesuítas e espanhóis); O Bibliotecário do Imperador, de Marco Luchesi (recria o Rio de Janeiro do fim do século XIX, quando o narrador tenta desvendar os últimos anos de Ignacio Raposo, bibliotecário de D. Pedro II); e, A Máquina de Madeira, de Miguel Sanches Neto (narra a história do padre paraibano que criou o protótipo da máquina de escrever no século XIX).

Temos aqui uma proposta de uma possível narrativa de uma História da Literatura da América Latina em que o entrecruzamento de história e ficção é preponderante. Em especial, se considerarmos a grande importância da relação entre essas duas áreas do saber na América Latina, já que tivemos nossa história imposta e através de narrativas ficcionais podemos reformulá-la de acordo com nossas vivências.

\section{Referências}

ARISTÓTELES. Poética. Trad. Eudoro de Souza. São Paulo: Nova Cultural, 1987 [cap. IX].

BAKHTIN, Mikhail. Epos e romance. In: - Questões de literatura e estética: a teoria do romance. Trad. Aurora Fornoni Bernardini et. al. São Paulo: Hucitec; UNESP, 1993 [pp. 397$428]$.

GRÜTZMACHER, Lukasz. Las Trampas del concepto "la nueva novela histórica" y de la retórica de la historia postoficial. Acta Poética. México, D.F, v.27, n.1, pp. 141-168. 2006. Disponível em: <http://132.248.101.214/html-docs/acta-poetica/27-1/141-168.pdf>.

HUTCHEON, Linda. Poética do pós-modernismo. Rio de Janeiro: Imago, 1991.

JAMESON, Fredric. O romance histórico ainda é possível? Trad. MADER, Hugo. Novos Estudos, n. 77 [online], março/2007, p. 185-203. Disponível em:

<http://www.scielo.br/pdf/nec/n77/a09n77.pdf>. 
LUKÁCS, Gyorgy. O Romance Histórico. Trad. Arlenice Almeida da Silva. São Paulo: Boitempo Editorial, 2011.

MENTON, Seymour. La nueva novela histórica de la América Latina. México: Fondo de Cultura Económica, 1992.

MIGNOLO, Walter. Lógica das diferenças e política das semelhanças: da Literatura que parece História ou Antropologia, e vice-versa. In. CHIAPPINI, Lígia \& AGUIAR, Flávio Wolf de. Literatura e História na América Latina. São Paulo: Edusp, 1993. p. 115-135.

MOREIRA, Maria Eunice. Uma História (Romanceada) da Literatura Brasileira. Revista Anpoll, Vol. 1, No 16 (2004). Pp. 225-240

NAVARRO, Márcia Hoppe. Romance de um ditador: poder e história na América Latina. São Paulo: Ícone, 1989.

PERKINS, David. História da literatura e narração. Cadernos do Centro de Pesquisas Literárias da PUCRS, Porto Alegre, v. 3, n. 1, mar. 1999. Série Traduções.

SARLO, Beatriz. Tempo passado: cultura da memória e guinada subjetiva. Trad. Rosa Freire d'Aguiar. Belo Horizonte: Ed. UFMG, 2007.

WHITE, Hayden. O texto histórico como artefato literário. In: Trópicos do discurso: ensaios sobre a crítica da cultura. São Paulo: EDUSP, 1994. [pp. 97-116]. 